\title{
Trends of laparoscopic gynecologic surgeries in a tertiary care center: A five-year retrospective study
}

\author{
Asmita Ghimire ${ }^{1}$, MD; Padam Raj Pant ${ }^{1,2}$, PhD; Nilam Subedi ${ }^{1}$, MD; Samriddha Raj Pant ${ }^{2}$, MBBS \\ ${ }^{1}$ Department of Gynecology \& Obstetrics, Grande International Hospital, Kathmandu, Nepal \\ ${ }^{2}$ Department of Gynecology \& Obstetrics, Institute of Medicine, Tribhuvan University Teaching Hospital, \\ Kathmandu, Nepal
}

\section{Corresponding author}

Asmita Ghimire, MD

Email: asmitaghimire4@gmail.com

Received 14 Oct 2018

Accepted 10 Dec 2018

\begin{abstract}
\section{Background:}

The use of laparoscopic surgery in modern gynecology has led to faster recovery, lesser hospital stay, and fewer complications. In this study, we aim to analyze the current trends in laparoscopic surgery, its indications, type of procedure and associated complications.
\end{abstract}

\section{Method:}

This is a retrospective study done in Grande International Hospital. All patients who underwent laparoscopic surgery over a duration of 5 years from July 2013 to June 2018 were analyzed.

\section{Result:}

There were a total of 419 laparoscopic surgeries ( 74 diagnostic, 345 therapeutic) performed. The most common age group of patients for diagnostic laparoscopy was 25-34 years and for therapeutic was 45-54 years. Therapeutic surgery was mostly performed for ovarian cyst $(144,41.74 \%)$. There were a total of 152 (44.06\%) laparoscopic hysterectomies performed. Complications which occurred during the surgery were insignificant $(p<0.01)$.

\section{Conclusion:}

Laparoscopic surgery has become the most common procedure for gynecological procedures over the years.

Keywords: hysterectomy, laparoscopy, ovarian cyst

\section{Introduction}

Laparoscopy is a modern surgical technique in which operations are done through small incisions using a laparoscope. Laparoscopy was first performed in dogs in the early 1900s by Dr. Georg Kelling, a German surgeon ${ }^{1}$. Dr. Hans Christian Jacobaeus, a Swedish surgeon, was the first to publish a description of laparoscopy in humans in $1910^{1}$. Laparoscopic surgery has thus evolved over the century and in the past four decades has become not just a diagnostic modality but an efficient instrument in treating benign and malignant cases.

Currently, laparoscopy is increasingly practiced by gynecologists throughout the world for ever evolving and challenging indications ${ }^{2-4}$. Approximately $80 \%$ of all gynecological surgical procedures can be done laparoscopically in advanced centers by experts trained in the procedures and in the best of the facilities ${ }^{5}$.

Laparoscopic surgery was started in those days in Grande International hospital when there were 
only few countable laparoscopic surgeries being performed in Nepal. Over the past five years there has been much increase in the trend of patients opting for laparoscopic surgery. This study is aimed at determining the current trend of laparoscopic surgeries, common indications, types of procedure and the surgical complications faced.

\section{Methods}

This was a retrospective study done in Grande International Hospital of surgeries performed over duration of 5 years (July 2013-June 2018). Information about patients age, diagnosis and indications of surgeries were reviewed from records from gynecology ward, medical record department and operation theatre. Complications of surgery and duration of hospital stays were also reviewed from ward records.

Preoperatively, baseline investigations were done. Baseline investigations included complete blood count, serology, urine analysis, chest $\mathrm{X}$-ray and electrocardiogram. All surgeries were done under aseptic measures under general anesthesia in Lloyd Davies position. Primary port was opened through Hasson technique or as per requirement. 2-3 secondary ports were made. Pneumoperitoneum was achieved with carbon dioxide electronic insufflator at $4-6 \mathrm{l} / \mathrm{min}$ and intraperitoneal pressure of $12-15 \mathrm{mmHg}$. Total laparoscopic hysterectomy, laparoscopic assisted vaginal hysterectomy, myomectomy, adenomyomectomy, radical hysterectomy, ovarian cystectomy, salpingo-oophorectomy, salpingectomy, tuboplasty, and diagnostic laparoscopy were done under standardized technique. A thorough review of the peritoneal cavity at the end of procedure was done. Dressing was done on $2^{\text {nd }}$ postoperative day and patients were followed till $7^{\text {th }}$ postoperative day. The data thus collected were entered to MS Excel and then imported to Statistical Package for Social Sciences (SPSS) version 19 for Windows (IBM Corp., Armonk, NY, USA). All reports were analyzed by simple frequency and percentage table. For complications $p$ value was calculated from chi square test and $p$ value $<0.05$ was considered statistically significant.

\section{Results}

There were a total of 419 laparoscopic surgeries (74 diagnostic, 345 therapeutic) during the study period. Over the years, the use of laparoscopy in gynecological surgeries has increased from 46 in $2013 / 2014$ to 150 in the year $2017 / 2018$.

The most common age group of patients for diagnostic laparoscopy was $25-34$ years followed by $15-24$ years.

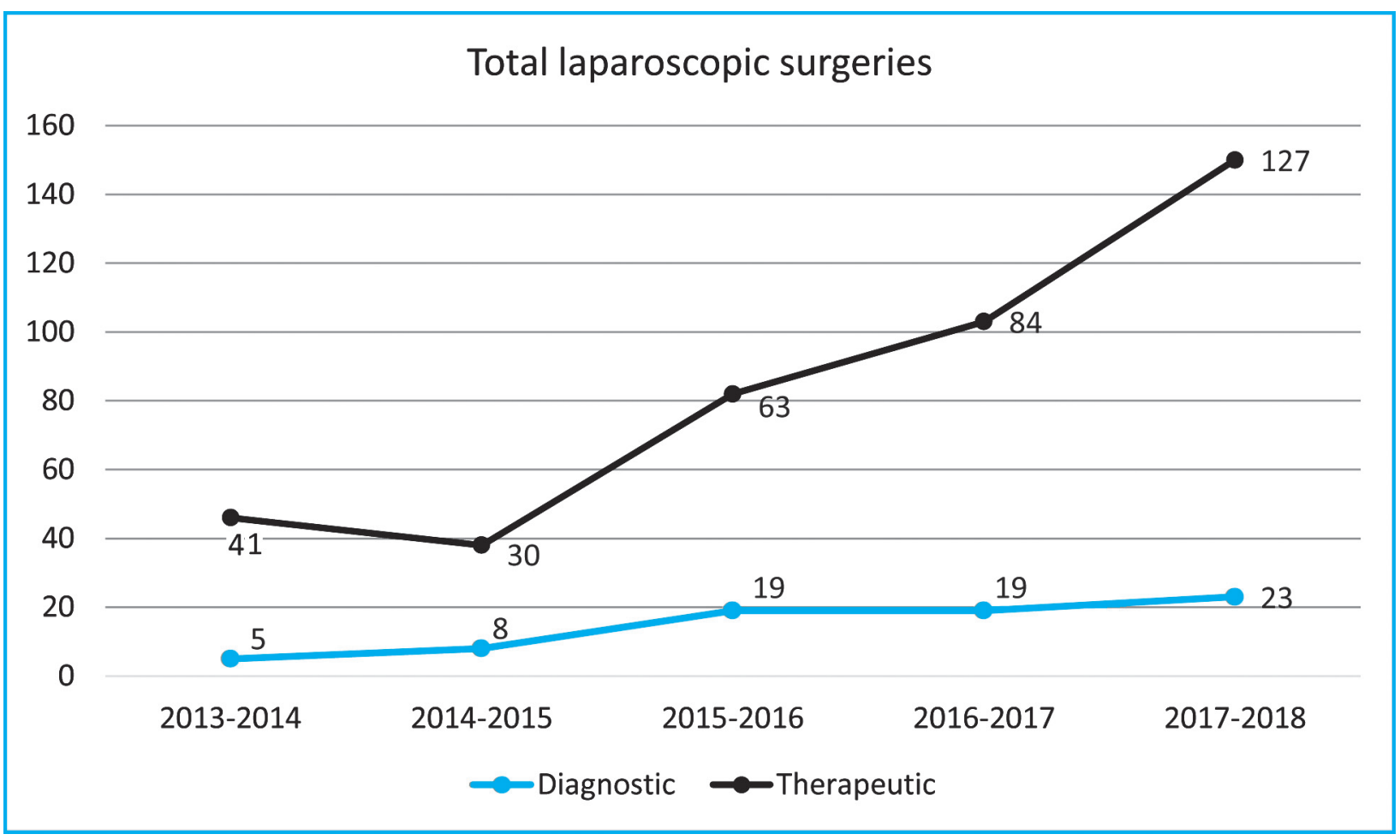

Figure 1. Trends of laparoscopic surgeries over five years 
Table 1. Age wise distribution of patients for diagnostic and therapeutic laparoscopic surgeries

\begin{tabular}{|c|c|c|}
\hline $\begin{array}{c}\text { Age group } \\
\text { (years) }\end{array}$ & $\begin{array}{c}\text { Diagnostic lapa- } \\
\text { roscopy }(\mathbf{n = 7 4 )} \\
\text { Frequency (\%) }\end{array}$ & $\begin{array}{c}\text { Therapeutic lapa- } \\
\text { roscopy }(\mathbf{n = 3 4 5 )} \\
\text { Frequency (\%) }\end{array}$ \\
\hline $15-24$ & $13(17.57 \%)$ & $49(14.20 \%)$ \\
\hline $25-34$ & $50(67.57 \%)$ & $70(20.29 \%)$ \\
\hline $35-44$ & $11(14.86 \%)$ & $98(28.40 \%)$ \\
\hline $45-54$ & 0 & $102(29.57 \%)$ \\
\hline$\geq 55$ & 0 & $26(7.54 \%)$ \\
\hline
\end{tabular}

For therapeutic laparoscopy the most common age group was $45-54$ years followed by $35-44$ years. The most common indication for therapeutic surgery was ovarian cyst ( $n=144,41.74 \%)$.

Table 2. Indications for therapeutic surgeries

Table 2. Indications for therapeutic surgeries
\begin{tabular}{|l|c|c|c|c|c|r|}
\hline \multicolumn{1}{|c|}{ Indications } & $\mathbf{2 0 1 3 - 2 0 1 4}$ & $\mathbf{2 0 1 4 - 2 0 1 5}$ & $\mathbf{2 0 1 5 - 2 0 1 6}$ & $\mathbf{2 0 1 6 - 2 0 1 7}$ & $\mathbf{2 0 1 7 - 2 0 1 8}$ & $\begin{array}{c}\text { No. of surgeries } \\
\text { (\%) }\end{array}$ \\
\hline Ovarian Cyst & 8 & 12 & 31 & 31 & 62 & $144(41.74 \%)$ \\
\hline Ectopic pregnancy & 0 & 3 & 0 & 5 & 10 & $18(5.22 \%)$ \\
\hline Fibroid uterus & 10 & 6 & 7 & 22 & 38 & $83(24.05 \%)$ \\
\hline Adenomyosis & 11 & 5 & 20 & 23 & 15 & $74(21.45 \%)$ \\
\hline Premalignant and malignant lesion & 10 & 3 & 4 & 3 & 1 & $21(6.09 \%)$ \\
\hline Post tubal ligation & 2 & 1 & 1 & 0 & 1 & $5(1.45 \%)$ \\
\hline \multicolumn{1}{|c|}{ Total } & 41 & 30 & 63 & 84 & 127 & $345(100 \%)$ \\
\hline
\end{tabular}

There were a total of 152 (44.06\%) laparoscopic hysterectomies performed.

Table 3: Types of therapeutic surgeries

\begin{tabular}{|l|c|c|c|c|r|r|}
\hline \multicolumn{1}{|c|}{ Surgeries } & 2013-2014 & 2014-2015 & 2015-2016 & 2016-2017 & 2017-2018 & $\begin{array}{c}\text { Total } \\
\text { surgeries (\%) }\end{array}$ \\
\hline Tubal sterilization & 0 & 0 & 0 & 0 & 1 & 1 (0.28\%) \\
\hline Tuboplasty & 2 & 1 & 1 & 0 & 1 & $5(1.45 \%)$ \\
\hline Salpingectomy & 0 & 3 & 1 & 2 & 12 & $18(5.22 \%)$ \\
\hline Cystectomy & 4 & 7 & 18 & 35 & 38 & $102(29.57 \%)$ \\
\hline Salpingo-oophorectomy & 1 & 2 & 3 & 1 & 3 & $10(2.90 \%)$ \\
\hline Myomectomy & 0 & 0 & 2 & 5 & 2 & $9(2.61 \%)$ \\
\hline Adenomyomectomy & 0 & 0 & 0 & 1 & 3 & $4(1.16 \%)$ \\
\hline Total Laparoscopic Hysterectomy & 18 & 7 & 32 & 36 & 59 & $152(44.06 \%)$ \\
\hline Laparoscopic Assisted Vaginal Hysterectomy & 16 & 10 & 5 & 3 & 6 & $40(11.59 \%)$ \\
\hline Radical Hysterectomy & 0 & 0 & 1 & 1 & 2 & $4(1.16 \%)$ \\
\hline \multicolumn{1}{|c|}{ Total } & 41 & 30 & 63 & 84 & 127 & $345(100 \%)$ \\
\hline
\end{tabular}

Though there were no significant complications (including death and disability) during the procedure. laparoscopy fell in the age group 25-34 years (Table 1) which was similar to study done in Nigeria?. This was common in this reproductive age group because the most common indication for diagnostic laparoscopy was infertility. For the therapeutic procedures most patients fell on the age group of 45-54 years (Table 1 ). This could also correlate to

Of the total laparoscopic procedures, $17.66 \%$ were diagnostic and $82.34 \%$ were therapeutic. $20 \%$ cases underwent diagnostic and $80 \%$ cases underwent therapeutic laparoscopic procedures. This showed that the use of laparoscopic surgeries is seen more in therapeutic rather than diagnostic procedures in this modern era.

Most of the patients undergoing diagnostic .

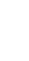


the fact that this is the age group where fibroid, adenomyosis and ovarian cysts are frequently found. And these were the common cases in our study.

For therapeutic surgery, ovarian cyst $(41.74 \%)$ was the most common followed by fibroid (24.05\%) and adenomyosis (21.45\%) (Table 2). Yuen et al. ${ }^{8}$ and Parker et al. ${ }^{9}$ demonstrated in their study that planned laparoscopic approach was successful in $95.2 \%$ patients with ovarian masses. The most common therapeutic procedure done was laparoscopic hysterectomy in our study $(44.06 \%)$ (Table 3). This is supported by a study done in Finland $^{10}$ where there was increasing trend of laparoscopic hysterectomy.

Of the total cases, 15 patient had complications and three of them were major complications. One of the patients had bowel injury during adhesiolysis for ovarian endometrioma for which colostomy was performed. This was detected early on $2^{\text {nd }}$ postoperative day due to development of peritonitis. Another had bladder injury and patient developed vesico- vaginal fistula. Ureteric injury occurred in a case of pyosalpinx. The latter two complications were detected one month after the surgery. Injury could have occurred because of the use of electrocautery. Repair of injury in both the cases were done. The serious complications in 3 cases $(0.72 \%)$ was less than the study done by Garry R et al. ${ }^{11}$ where the bladder and ureteric complication was $2.1 \%$ and $0.5 \%$ respectively. However, bowel complication

Table 4. Complications of Laparoscopic surgery

\begin{tabular}{|c|c|c|}
\hline Complications & Number (\%) & $p$ value $(\chi 2)$ \\
\hline Vomiting & $10(2.38 \%)$ & \\
\hline Port site infection & 0 & \\
\hline Port site hernia & $1(0.23 \%)$ & \\
\hline Vault infection & 0 & \\
\hline Vascular Injury & 0 & \\
\hline Bladder Injury & $1(0.23 \%)$ & \\
\hline Ureteric Injury & $1(0.23 \%)$ & \\
\hline Bowel Injury & $1(0.23 \%)$ & \\
\hline Conversion to laparotomy & $2(0.49 \%)$ & \\
\hline Total & $15(3.58 \%)$ & \multirow{2}{*}{$<0.01$} \\
\hline No complications & 404 (96. 42\%) & \\
\hline
\end{tabular}

was similar to our study (0.2\%). There were only two $(0.49 \%)$ cases that required conversion to laparotomy. Conversion indications included: presence of dense adhesions of bladder to the anterior wall of the uterus and obesity in both the cases. This rate was much less than other quoted in other studies ${ }^{12-14}$. In our study, the lesser rate of conversion to open laparotomy could be due to proper case selection. Vomiting was seen in ten cases, which most commonly occurred in patients of diagnostic laparoscopy who had dense pelvic adhesions and in them antibiotic was instilled in the abdominal cavity.

The duration of hospital stay was on an average 1.5 days for diagnostic laparoscopy and 2.5 days for therapeutic laparoscopic surgeries. This was similar to the study done by Bajracharya et al. ${ }^{12}$ but less than in the study done by Sarath et al. ${ }^{15}$ and Badejko et al. ${ }^{16}$ which stood at 2-6 days. The shorter hospital stay in our study positively correlates with less complications and consequently, faster recovery.

\section{Conclusion:}

Laparoscopic procedures over the years have become a popular procedure among patients and surgeons due to minimal pain, less complications, shorter hospitalization and faster recovery.

\section{Reference:}

1. Litynski GS. Laparoscopy--the early attempts: Spotlighting Georg Kelling and Hans Christian Jacobaeus. JSLS. 1997;1(1):83-5.

2. Schreuder HW, Verheijen RH. Robotic surgery. BJOG. 2009; 116(2):198-213.

3. Holloway RW, Ahmad S, DeNardis SA, Peterson LB, Sultana N, Bigsby GE IV, et al. Robotic-assisted laparoscopic hysterectomy and lymphadenectomy for endometrial cancer: Analysis of surgical performance. Gynecol Oncol. 2009;115(3):447-52.

4. Darzi A, Mackay S. Recent advances in minimal access surgery. BMJ. 2002; 324(7328):31-34.

5. O'Dowd M. Standards for gynecologic surgery. J Obstet Gynaecol India. 2013; 63(1):7-13.

6. Omokanye LO, Olatinwo AWO, Ibrahim S, Durowade KA, Biliaminu SA, Abdul IF. Gynecological laparoscopic surgeries: A 4-year audit at the University of Ilorin Teaching Hospital, Nigeria. Trop J Obstet Gynaecol. 2017;34(1):49-53.

7. Constance E. Shehu, Sulaiman B. A five-year audit of gynecological laparoscopy at Usmanu Danfodiyo 
university teaching hospital, Sokoto, Nigeria. Eur J Pharm Med Res. 2016; 3(7):76-81.

8. Yuen PM, Yu KM, Yip SK, Lau WC, Rogers MS, Chang A. A randomized prospective study of laparoscopy and laparotomy in the management of benign ovarian masses. Am J Obstet Gynecol. 1997;177(1):109-14.

9. Parker J, Bethune M, Lau P, Permezel M, Tan J, Byrne D. Operative laparoscopic management of adnexal cysts: Initial experience at the Royal Women's Hospital 1991-1994. Aust N Z J Obstet Gynaecol. 1996; 36(1):31-5.

10. Brummer TH, Seppälä TT, Härkki PS. National learning curve for laparoscopic hysterectomy and trends in hysterectomy in Finland 2000-2005. Hum Reprod. 2008;23(4):840-5.

11. Garry R, Fountain J, Brown J, Manca A, Manson S, Sculpher $M$, et al. EVALUATE hysterectomy trial: A multicenter randomized trial comparing abdominal, vaginal and laparoscopic methods of hysterectomy. Health Technol Assess. 2004;8 (26):1-154.
12. Bajracharya N, Dangal G, Karki A, Pradhan H, Shrestha R, Bhattachan, et al. Experience of laparoscopic gynecological surgeries at Kathmandu Model Hospital. NJOG. 2017; 23(1):22-5.

13. Rosen M, Brody F, Ponsky J. Predictive factors for conversion of laparoscopic cholecystectomy. Am J Surg 2002; 184(3): 254-8.

14. Cwik G, Skoczylas T, Wyroślak-Najs J, Wallner G. The value of percutaneous ultrasound in predicting conversion from laparoscopic to open cholecystectomy due to acute cholecystitis. Surg Endosc 2013; 27(7):2561-8.

15. Sarath BG, Vnkata S. Adoption of laparoscopy in a rural medical college hospital: Minimal access surgery for masses a reality. J Womens Health Issues Care. 2013; 2(4):1-4.

16. Badejko OO, Adeyemi AB, Kuti O, Ijarotimi O, Loto $\mathrm{OM}$, Awowole IO, et al. Operative gynecologic laparoscopy in Ile- Ife, Nigeria: Preliminary experience. J Gynecol Surg. 2013; 29(4):186-9. 